\title{
Power Quality Improvement by Shunt Active Performance Filters Emulated by Artificial Intelligence Techniques
}

\author{
Radek Martinek, Jakub Manas, Jan Zidek and Petr Bilik \\ Department of Cybernetics and Biomedical Engineering \\ Faculty of Electrical Engineering and Computer Science, VSB - Technical University \\ Ostrava, Czech Republic \\ e-mail: \{radek.martinek; jakub.manas;jan.zidek; petr.bilik\}@vsb.cz
}

\begin{abstract}
This article is focused on progressive strategies of shunt active performance filters with intension to compensate higher harmonic currents of non-linear load. The authors of this article deal with usage of a combination of fuzzy system techniques and artificial intelligence, which is also known as Adaptive Neuro Fuzzy Interference Systems- ANFIS for improve in terms of quality of electrical energy in supply network. Within the executed experiments there was created a complex adaptive system based on the ANFIS structure. Authors have been examining different structures of the ANFIS network (structure). Experimental results based on real signals are showing up, that mentioned types of control with the use of ANFIS reach very good compensation attributes of the harmonic currents of non-linear load. These control strategies of the active shunt filter are compared on a base of total THD harmonic distortion of current networks after the compensation.
\end{abstract}

Keywords-Adaptive Neuro Fuzzy Inference Systems ANFIS;Total Harmonic Distortion - THD;Power Quality;Shunt Active Power Filter- SAPF.

\section{INTRODUCTION}

Currently, there is a big attention given to a problem of adaptive systems, because many of modern applications need this kind of a progressive accession of adaptation. Topicality of examined problem corresponds to improvement of a microprocessor technique performance:multi-core processors [2], Field Programmable Gate Array - FPGA [2]. In fact, low performance of processors was the main limiting factor in usage of the sophisticated complex adaptive filters. In 2013, we can say that the age of changes is coming, which is evocated with several trends in area of information technologies.

The idea of the adaptation comes from attributes of the bioplasm, it's ability of living organisms to adapt their behavior to changes in an environment they live in, especially, when these changes are adverse. This phenomenon is commonly called learning. To this group of systems, which are capable of adaptation we can also count mechanical systems beside of those biological ones, then we are talking about so called machine learning.[3] The ability to learn is sometimes considered as a definition for intelligence, see [3]. So it's genuine that there is a big effort to acquire such an attribute also to technical systems. These technical adaptive systems are characterized by the ability to adapt their parameters according to anactual information about controlled system or executed signal. Exactly these abilities are used by the authors of this article to predict the changes of current in supply networks which are caused by connecting of non-linear loads. The article is primarily focused on systems which use the combination of fuzzy system techniques [4] and the artificial intelligence [3]. The authors deal with use of Adaptive Neuro-fuzzy Interference system based on ANFIS control of three-phase power filter [6] for harmonic mitigation [4].

\section{CURRENT StATUS OF EXAMINED PROBLEM}

Currently, the quality of electrical energy [7] is still more and more discussed question. Harmonically [8] generated non-linear appliances [8] are some kind of pollution of the supply networks [7].To these non-linear loads belong:

- controlled actuations, motor starters

- $\quad$ electric lights

- $\quad$ PCs, UPS and other electric devices

All of these devices are generating undesirable harmonic currents to the supply network. Caused by this, there is a voltage distortion in the supply network and it also causes an aggravation in quality of electrical energy. In this article, the most important marker of electrical energy quality will be harmonic distortion of current [9]. Distortion of the supplynetwork can cause some critical damage, for example:

- $\quad$ overheating of transformers and motors (even if they are correctly dimensioned)

- $\quad$ possible oscillation of motors (vibrations can appear)

- $\quad$ in case of magnetic switchers, device can be turned off

- $\quad$ flicker, PC failures (loss of data).

All effects caused by bigger distortion of the supply network lead to economic losses [7]. Therefore, it is very important to mitigate dominant harmonics to the specifications outline in IEEE 519-1992 harmonic standard [10]. Today, there are 2 basic types of higher harmonic elimination- passive [11] and active [12] filter.

\section{ShUNT ACtIVE PERFORMANCE FILTERS WITH ANFIS}

The active shunt filter represent additional performance electric switcher [15] plugged to a non-linear load, see fig. 1. The adaptive system is here to watch and predict the changes of harmonics, which are created by plugging the non-linear loads, or let us say to adapt to network current changes in time. Incoming switcher current is driven to produce same levels of the harmonics as the non-linear load with the help of ANFIS, but in opposite phase. These 2 levels of 
harmonics eliminate each other in a point where they meet. After this, the final current is without undesired harmonics. With such a method, current taken from the network is filtered and this way also voltage deformations caused by the load can be eliminated and the effectiveness of the network will be improved too. The principle of this action is already known for several decades, but the realization was possible just after the arrival of modern and fully controlled components, like are modern IGBT [16], transistors, tyristor modules IGCT [16] supplemented by anti-shunt diodes [17]. Better description of the shunt active filters activity can be found in $[11,14,17]$.
In fig. 1 is shown simplified principal scheme of the shunt active filter for three-phase system, which is controlled by ANFIS. The filter consists of the controlled current generator (rectifier with PWM [17]) plugged shunt to a load. The active filter doesn't need external source of power supply, capacitor is charged by controlling periphery. For basic processing are used well known practices such a Clarke transformation [14], Fourier transform [18], linear filtration [19], we can mark them as a conventional processing (see fig. 1 ). Better description of these DSP methods is beyond area of this articles topic, you can find more information in $[14,18,20]$.

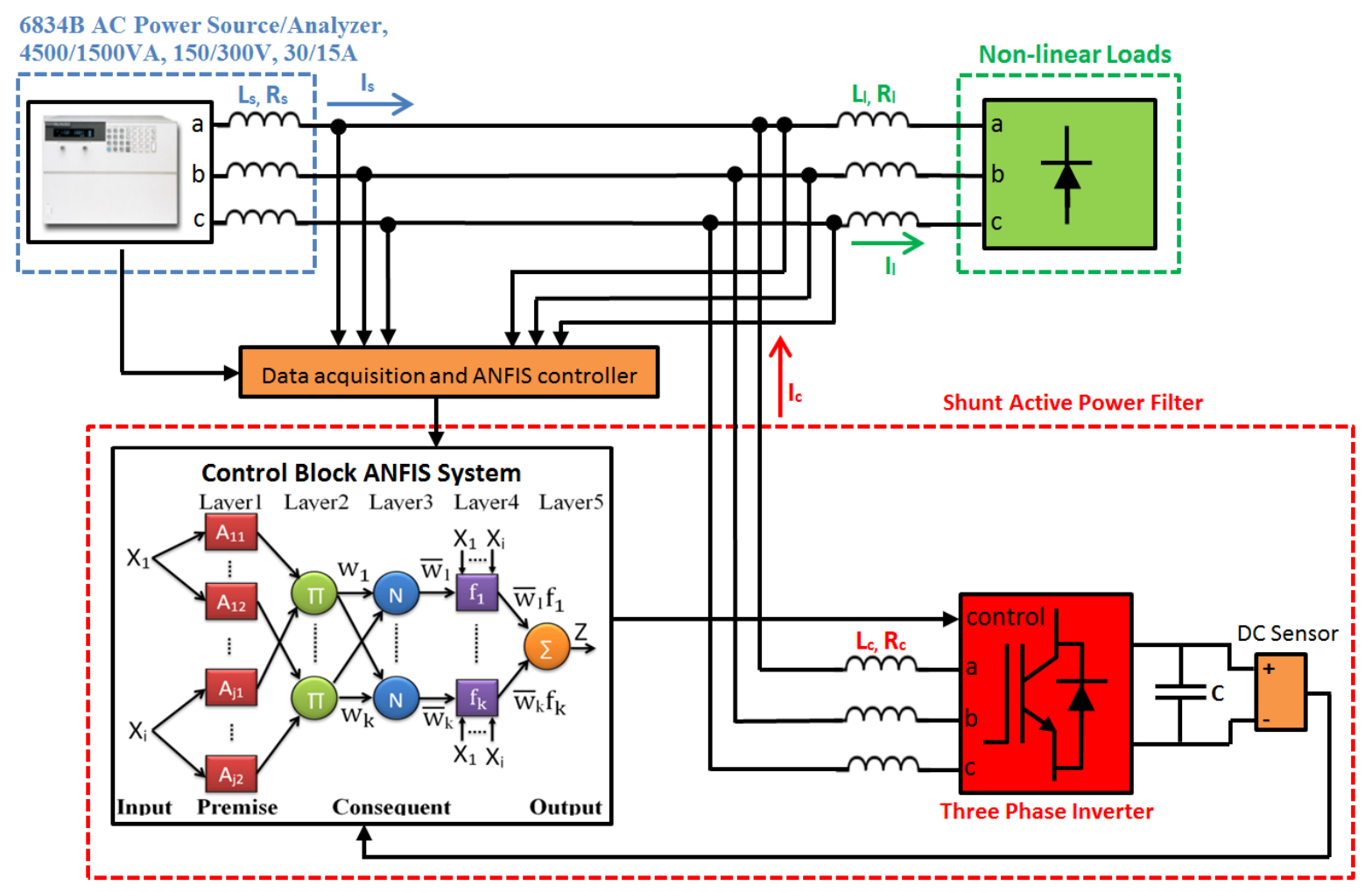

Figure 1. Simplified principal scheme of the shunt active filter for three-phase.

\section{ADAPTIVE NEURO FUZZY INFERENCE SYSTEMS}

ANFIS (Adaptive Neuro-Fuzzy Inference System) [23] represents a forward, adaptive neural network that is functionally equivalent to the fuzzy inference system of the Sugeno type (Takagi-Sugeno) [22]. A Two Rule Sugeno ANFIS has rules of the form:

$$
\begin{aligned}
& \text { If } x \text { is } A_{1} \text { and } y \text { is } B_{1} \\
& \text { THEN } f_{1}=p_{1} x+q_{1} y+r_{1} \\
& \text { If } x \text { is } A_{2} \text { and } y \text { is } B_{2} \\
& \text { THEN } f_{2}=p_{2} x+q_{2} y+r_{2}
\end{aligned}
$$

where $x$ and $y$ are the inputs, $A_{\mathrm{i}}$ and $B_{\mathrm{i}}$ are the fuzzy sets, $f_{\mathrm{i}}, i=1,2$ are the output of fuzzy system, and $p_{\mathrm{i}}, q_{\mathrm{i}}$ and $r_{\mathrm{i}}$ are the design parameters which are determined during the training process.

The ANFIS architecture to implement these two rules is shown in fig. 2 [21], inwhich a circle indicates a fixed node whereas a square indicates an adaptive node. As figure illustrates, ANFIS architecture consists of five layers [3].

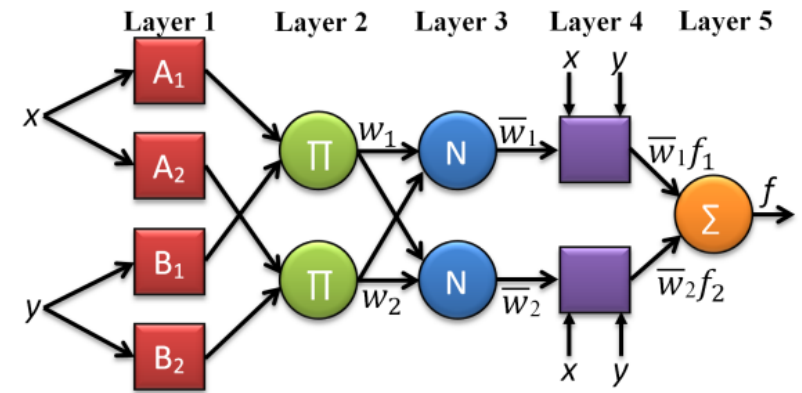

Figure 2. Simple T-S FIS system. 
Mathematical derivation and description of function of single layers (fig. 2) is well-known in common and good described in a number of specialized publications, e.g. in [1, $4,21,22]$. The authors of paper address to the detailed description of ANFIS in their own publication [20].

\section{DESCRIPTION OF EXPERIMENTAL WORKSTATION}

To verify functionality of the designed ANFIS system, three-phase voltage and current waveforms have been measured. For this has been used the experimental workstation with programmable source HP6834B [25] (see fig. 3) and with developed IED (intelligent electronics device) which allow us to measure the parameters of the power energy quality. To source have been connected different nonlinear loads.

For automatic tests was the source controlled remotely with developed IED using GPIB interface. The developed IED allows to measure up to three voltages and currents with sampling frequency up to $40 \mathrm{kS} / \mathrm{s}$ for a channel. Input voltage levels are adapted to measure on voltage transducers $(57,7 / 100 \mathrm{~V})$ and also to a direct measuring in low voltage networks (230/400 V). Current levels are adapted to measure on current transducers $(1 / 5 \mathrm{~A})$ or for the use of current clamps (20/200A).

Every input has its own anti-aliasing filter to keep a sampling theorem. All measuring ranges were calibrated with NI 9225 [30] and NI9227 [31] modules.The developed application in IED allows to measure and evaluate the power quality parameters according to actual standards IEC 610004-30, IEC 61000-4-7, IEC 61000-4-15 and EN 50160 [33]. To application were implemented the techniques of the ANFIS system what has allowed us to watch its results in real-time.

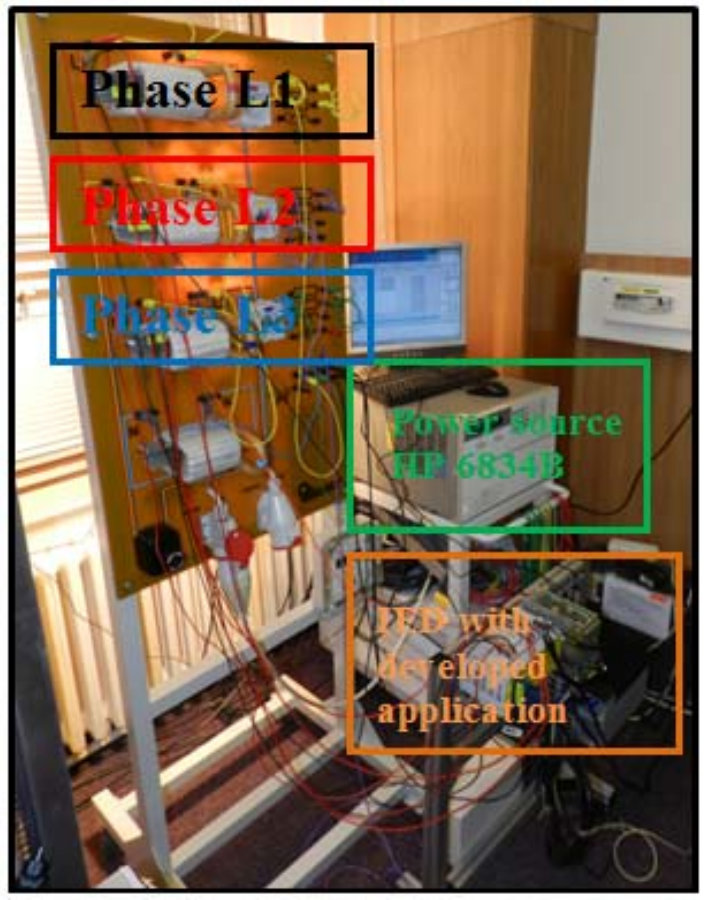

Figure 3. Experimental workplace.
The programmable source HP6834B allows togenerate three-phase sinus waveforms up to 300V/5A amplitude and frequency up to $5 \mathrm{kHz}$ (100 harmonic for $50 \mathrm{~Hz}$ ).

\section{RESULTS OF EXECUTED EXPERIMENTS}

Within the executed experiments have been examined different networks (structures) of ANFIS. The review of used network models is in tab. 1. For the ANFIS system buildinghavebeen used ANFIS functions [26], for training (estimation) EVALFIS function [27]. Better description of work with functions ANFIS and EVALFIS in MATLAB [28] environment can be found in $[26,27,28]$.

TABLE I. THE REVIEW OF USED ANFIS MODELS.

\begin{tabular}{|ccccc|}
\hline ANFIS Model & A & B & C & D \\
\hline number of nodes & 21 & 35 & 53 & 75 \\
\hline $\begin{array}{c}\text { number of linear } \\
\text { parameters }\end{array}$ & 12 & 27 & 48 & 75 \\
\hline $\begin{array}{c}\text { number of nonlinear } \\
\text { parameters }\end{array}$ & 12 & 18 & 24 & 30 \\
\hline $\begin{array}{c}\text { total number of } \\
\text { parameters }\end{array}$ & 24 & 45 & 72 & 105 \\
\hline number of fuzzy rules & 4 & 9 & 16 & 25 \\
\hline
\end{tabular}

In fig. 4 are reference current waveforms through the single phases.For a better readability of executed experiments was presented length of time window $0,05 \mathrm{~s}$. The waveforms of single phases are marked by different colors: phase A is blue,phase B is red and phase C is black.

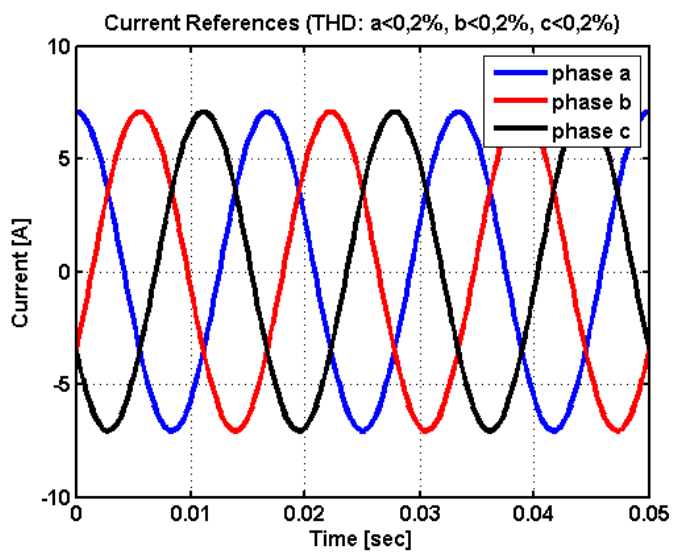

Figure 4. Reference voltage process.

Infig.5 are current waveforms through single phases after the connection of non-linear load. The authors plugged to the experimental supply network real non-linear loads (for example PC, regulated actuations, e.t.c.) see chapter 2.

This way were captured the real hardly distorted waveforms of the current which we can, from a view of used ANFIS system, consider as a primary waveforms. The $\mathrm{THD}_{\mathrm{I}}$ distortions are for phase $a=97,6 \%, b=99,5 \%$ a c $=96,8 \%$. 


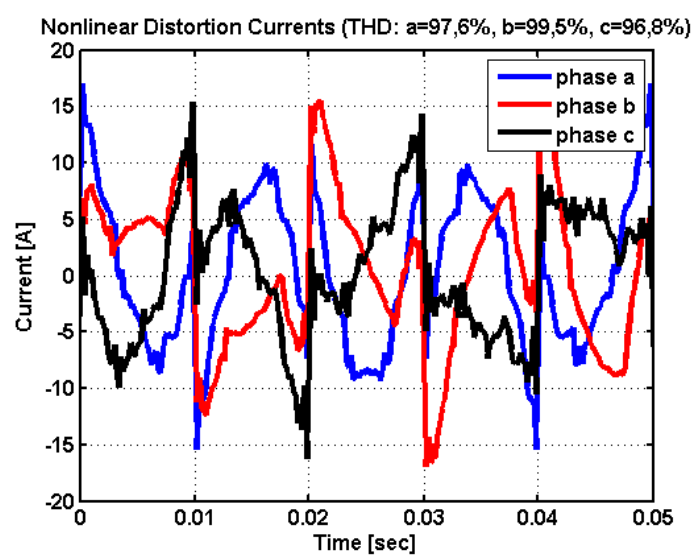

Figure 5. Primary current waveforms from non-linear load.

Infigures from 6 to 7 are displayed final waveforms of reconstructed currents for ANFIS models $\mathrm{A}$ and ANFIS models B.

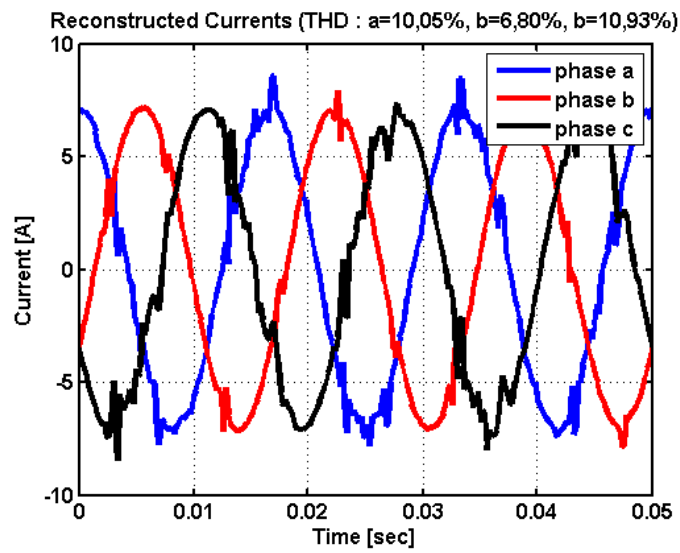

Figure 6. Reconstructed current waveforms for ANFIS model A.

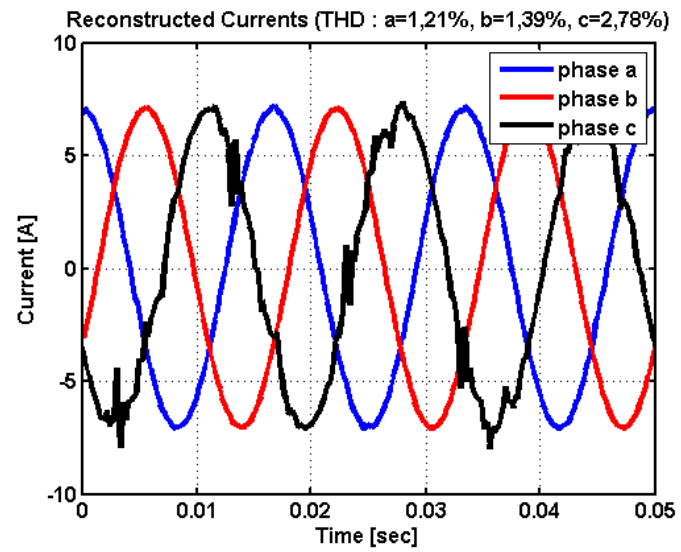

Figure 7. Reconstructed current waveforms for ANFIS model B.

If we compare the results of single ANFIS models, we can declare that the worst results have reached the ANFIS model A, see fig.6. This is caused by simplicity of used model (see tab.1), however this model has the lowest requirements for calculations. If we compare the results of other ANFIS models B, C and D we can allege that those models are very equal to each other, see tab. 2 . More difficult models bring us just a bit of an improvement. This is, however, paid by huge increase of requirements for calculations (see tab. 1) so from the view of own implementation they appear as inconvenient.

The frequency spectra of the source current before and after the compensation are compared in fig. 8 where the amplitude of each harmonic is represented in a percentage to the fundamental.

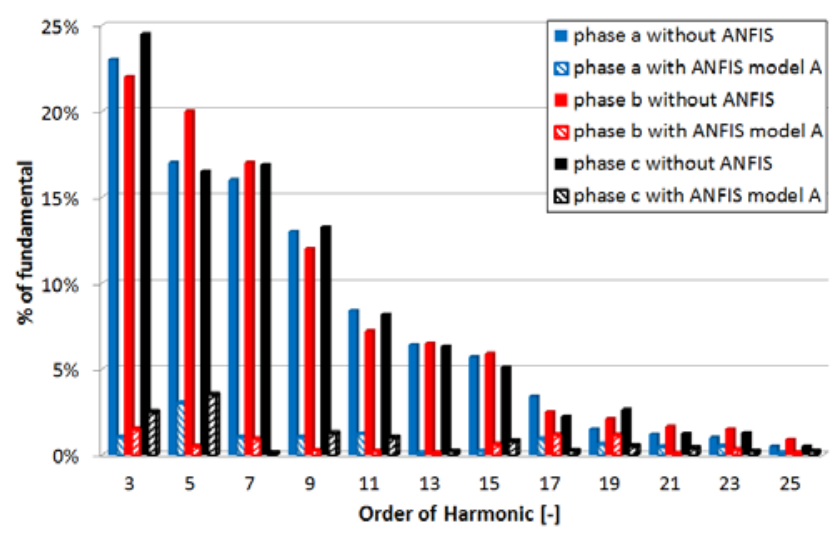

Figure 8. Comparision of amplitude current spectras from non-linear load and reconstructed current waveforms using the ANFIS model A.

With the other ANFIS models the THD values have been really low, so their presence in fig. 8 would have just a small relegating value. The results of single executed ANFIS models are nicely presented in tab. 2 .

TABLE II. RESULTS OF EXECUTED EXPERIMENTS

\begin{tabular}{|cccc|}
\hline \multicolumn{4}{|c|}{ Improvement of the THD Value } \\
\hline $\begin{array}{c}\text { Phase a } \\
\text { Without }\end{array}$ & Phase b & Phase c \\
\hline $\begin{array}{c}\text { ANFIS } \\
\text { ANFIS }\end{array}$ & $97,6 \%$ & $99,5 \%$ & $96,8 \%$ \\
\hline $\begin{array}{c}\text { ANFIS } \\
\text { model B }\end{array}$ & $10,05 \%$ & $6,80 \%$ & $10,93 \%$ \\
\hline $\begin{array}{c}\text { ANFIS } \\
\text { model C }\end{array}$ & $0,64 \%$ & $0,75 \%$ & $1,21 \%$ \\
\hline $\begin{array}{c}\text { ANFIS } \\
\text { model D }\end{array}$ & $0,31 \%$ & $0,62 \%$ & $0,86 \%$ \\
\hline
\end{tabular}

\section{SUMMARY}

This article was dedicated to a new control strategy of shunt active performance filters. The effort of the authors was to design system, which would effectively compensate higher harmonic currents of non-linear load in modern power networks, where is impossible to predict frequencies of disturbing signals and these frequencies also change in time.

The executed experiments tested the functionality of designed ANFIS system. The system was reaching satisfying results. The THD of the source current after compensation is 
for ANFIS model A approx. 10\%. For ANFIS models B, C a $\mathrm{D}$ is THD approx. $1 \%$ which is less than $5 \%$, the harmonic limit imposed by the IEEE-519 [10] and IEC-61000-3 [29] standards.

The used method provides really better response than $\mathrm{p}-\mathrm{q}$ method [13]in some cases because it is easier to implement on a microprocessor. Also when there are variable frequencies because of the supply network instability, used method will follow basic frequency in a moment when the frequency loop will be closed.

The adaptive Neuro-Fuzzy controller training and fundamental wave assessment was done by using offline training method. Next step will lead to investigation of the possibilities in applying online training method to track harmonics which vary in time and are located in power systems.

\section{ACKNOWLEDGMENT}

This researchwas supported in part by The Ministry of Education, Youth and Sports of Czech Republic under the project KONTAKT II registration numberLH12183 and project SGS no. SP2013/203 VSB-TU Ostrava, FEECS.

\section{REFERENCES}

[1] J. Patel, R. Gianchandani, "ANFIS Control for Robotic Manipulators: Adaptive Neuro Fuzzy Inference Systems for Intelligent Control." LAP LAMBERT Academic Publishing (25 Nov 2011), 88 pages, ISBN-13: 978-3846591710

[2] Korf, Richard E. Artificial intelligence search algorithms. Chapman \& Hall/CRC, 2010.

[3] Hands-on Experience with a Sorting ApplicationN. K., Bett, J. N. Nderu, and P. K. Hinga, "Adaptive Neuro-fuzzy Inference system based control of three-phase hybrid power filter for harmonic mitigation." In Journal: Emerging Technology and Advanced Engineering, pp. 75-81, ISSN 2250-2459, Volume 2, Issue 8, August 2012. Article (CrossRef Link)

[4] L. WenNa, W. PeiFeng, L. Yang, "A Method of Adaptive Colored Noise Cancellation Based on ANFIS."International Conference on Image Analysis and Signal Processing, 2009. IASP 2009, Taizhou, pp. 386 - 388, ISBN: 978-1-4244-3987-4. Article (CrossRef Link)

[5] Zhang, Yu, Yupeng Tang. "Active Power Filter Based on Adaptive Detecting Approach of Harmonic Currents." Journal of Electromagnetic Analysis and Applications 1.4 (2009): 240-244. Article (CrossRef Link)

[6] B. Dixit, Amit Yadav, Electrical Power Quality, First, 2010, p. 172, ISBN : 978-93-80386-74-4.

[7] D. Chapman, "Power Quality Application Guide, Harmonics Causes and Effects." March 2001, Copper Development Association. Article (CrossRef Link)

[8] S. Fukuda, K. Muraoka, T. Kanayama, "Adaptive learning based current control of active filters needless to detect current harmonics."In Applied Power Electronics Conference and Exposition, 2004. APEC'04. Nineteenth Annual IEEE (Vol. 1, pp. 210-216). IEEE. Article (CrossRef Link)

[9] IEEE Recommended Pratices and Requirements for Haronic Control in Electrical Power Systems. IEEE std 519-1992 (CrossRef Link)

[10] P.Brandstetter, Active power filter, VSB-TU Ostrava,(CrossRef Link)

[11] Z.l Salam, "Hybrid Active Power Filter." 184 pages, LAP Lambert Academic Publishing (17 Aug 2009), ISBN-13: 978-3838307510.

[12] R. Martinek, J. Zidek, "Use of Adaptive Filtering for Noise Reduction in Communication systems," In Conference Proceeding: The International Conference Applied Electronics (AE), pp. 1-6, ISBN
978-80-7043-865-7, ISSN 1803-7332, INSPEC Accession Number: 11579482, Pilsen, Czech Republic, 8-9 September 2010. Article (CrossRef Link)

[13] Z. Paclt, "Control strategy of a shunt active power filter", $\mathrm{PhD}$ thesis, CVUT, 2011.

[14] S. Kalaschnikow, S. Hansen, L. Asiminoaei, H. G. Moos, "Active compensation of harmonics in industrial applications". In Electrical Power Quality and Utilisation, 2007. EPQU 2007. 9th International Conference on (pp. 1-6). IEEE. Article (CrossRef Link)

[15] L. A. Morán, J. W. Dixon, J. R., Espinoza, R. R. Wallace, "Using active power filters to improve power quality."In 5th Brazilian Power Electronics Conference (pp. 501-511). Article (CrossRef Link)

[16] M. Rashid, "Power Electronics Handbook." Hardbound, 1362 Pages, Published: December 2010, Butterworth

[17] M. J. Roberts, "Signals and Systems: Analysis Using Transform Methods and MATLAB." USA, The McGraw-Hill Companies, 2008, 1026 p. ISBN 0-07-293044-6.

[18] R. Martinek, J. Zidek, "A System for Improving the Diagnostic Quality of Fetal Electrocardiogram, "In Journal: Przeglad Elektrotchniczny (Electrical Review), R. 88 NR 5b/2012, pp. 164173, ISSN 0033-2097, Warszawa, Poland, May 2012. Article (CrossRef Link)

[19] J. G. Proakis, D..K. Manolakis, "Digital Signal Processing: Principles, Algorithms, and Applications." Pearson; 4 edition (15 Feb 2006), 948 pages, ISBN-13: 978-0132287319.

[20] R. Martinek, J. Zidek, "Refining the diagnostic quality of the abdominal fetal electrocardiogram using the techniques of artificial intelligence,"In Journal: Przeglad Elektrotchniczny (Electrical Review), R. 88 NR 12b/2012, pp. 155-160, ISSN 0033-2097, Warszawa, Poland, December 2012. Article (CrossRef Link)

[21] O. Castillo, P. Melin, "Type -2 Fuzzy Logic: Theory and Applications." 2008, XIV, 244 p. 188 illus, ISBN 978-3-540-76283-6.

[22] M. Hammer, O. Janda, J. Ertl. "Selected Soft-Computing Methods in Power Oil Transformer Diagnostics - part 1. In Journal: Elektrorevue. pp. 1-13, ISSN 1213-1539, 2012. Article (CrossRef Link)

[23] A. Shukla, R. Tiwari, R. Kala, "Towards Hybrid and Adaptive Computing." 1st Edition, 2010, 450 p., 138 illus, ISBN 978-3-64214343-4.

[24] HP - Agilent 6834B, Agilent 6834B Specifications. (CrossRef Link)

[25] MathWorks, Matlab R2012b - Adaptive Noise Cancellation, demonstration of adaptive nonlinear noise cancellation using the Fuzzy Logic Toolbox ${ }^{\mathrm{TM}}$ functions ANFIS and GENFIS1. (CrossRef Link)

[26] MathWorks, Matlab R2012b - Fuzzy Logic Toolbox, web: (CrossRef Link), MathWorks, Matlab R2012b - genfis1 and anfis - Generate Fuzzy Inference System structure from data using grid partition, web: (CrossRef Link)

[27] International Statndard IEX 61000-3-3, 2002, (CrossRef Link)

[28] R. Martinek, M. Al-Wohaishi, J. Zidek, "Software Based Flexible Measuring Systems for Analysis of Digitally Modulated Systems," In Conference Proceedings: The 9th Roedunet International Conference, RoEduNet, pp. 397-402, ISBN 978-1-4244-7335-9, ISSN 2068-1038, Sibiu, Romania, 24-26 June 2010. Article (CrossRef Link)

[29] NI 9225, 3-Channel, 300 Vrms Analog Input Module (CrossRef Link)

[30] NI 9227, 4-Channel Current Input C Series Module (CrossRef Link)

[31] Electromagnetic compatibility (EMC), INTERNATIONAL STANDARD IEC, (CrossRef Link)

[32] Czech version of the European Standard EN 50160:1999. (CrossRef Link) 